\title{
Direitos reais secundários e planejamento urbano: uma alternativa às estratégias clássicas de pensar o território
}

\author{
Secondary real rights and urban planning: an alternative to the classic \\ strategies of thinking about territory
}

Anderson Henrique Vieira[a] (D), Larissa da Silva Ferreira Alves[a] (D)

[a] Universidade do Estado do Rio Grande do Norte (UERN), Pau dos Ferros, RN, Brasil

Como citar: Vieira, A. H., \& Alves, L. S. F. (2020). Direitos reais secundários e planejamento urbano: uma alternativa às estratégias clássicas de pensar o território. urbe. Revista Brasileira de Gestão Urbana, 12, e20200005. https://doi.org/10.1590/2175-3369.012.e20200005

\section{Resumo}

O mais amplo dos institutos de direito real secundário, a enfiteuse, se insere de modo confortável em um rol de titularidades aptas a ampliar o acesso ao solo urbano bem como fomentar a segurança habitacional pela grande extensão de direitos de propriedade que dispõe o enfiteuta. Além disso, traz incluso o dever jurídico de edificar e melhorar o imóvel, podendo servir como uma eficiente ferramenta de gestão urbana pelas suas características de flexibilidade, justiça e funcionalização. Nesse cenário, o desenvolvimento deste instituto, conjugado ao planejamento urbano, é fator primordial para minimizar a perspectiva exclusiva, excludente e absoluta da propriedade e favorecer a promoção de políticas públicas de acesso à terra. Assim, objetiva-se neste artigo compreender como o planejamento urbano, estruturado sob o desenvolvimento de direitos reais secundários, pode contribuir para democratizar o espaço urbano. Para tanto, aplicou-se o método dedutivo e pesquisa bibliográfico-documental como procedimentos metodológicos. 0 principal resultado indica que a política liberal não admite um maior desenvolvimento dos direitos reais secundários, estruturando o planejamento urbano, porque tal arranjo é mais conectado com uma dimensão social/funcional da cidade e vai de encontro ao que o capital precisa manter para justificar e legitimar sua violência simbólica e fática de exploração.

Palavras-chave: Direitos reais. Políticas públicas. Planejamento Urbano.

\section{Abstract}

The widest of the institutes of secondary real law, the emphyteusis, fits comfortably into a list of ownership capable of extending access to urban land, as well as promoting housing security, due to the large extension of property rights available to the emphyteusis. In addition, it brings the legal duty to build and improve the property, which can serve as an efficient tool for urban management as long as its characteristics of flexibility, justice and functionality. In this scenario, the development of this institute, together with the urban planning, is a primordial factor to minimize the exclusive, exclusive and absolute perspective of the property and to favor the promotion of public policies of access to land. Thus, the present work aims to understand how urban planning, structured under the development of secondary real rights, can

AHV é bacharel em Direito, mestrando em Planejamento e Dinâmicas Territoriais no Semiárido, e-mail: andersonhvieira@gmail.com LSFA é licenciada em Geografia, doutora em Geografia, e-mail: larissaferreira@uern.br 
contribute to democratizing urban space. To this end, the deductive method and bibliographicdocumentary research were applied as methodological procedures. The main result indicates that liberal politics does not admit a greater development of secondary real rights, structuring urban planning, because such an arrangement is more connected to a social/functional dimension of the city and goes against what the capital needs to maintain in order to justify and legitimize its symbolic and factual violence of exploitation.

Keywords: Real rights. Public policy. Urban Planning.

\section{Introdução}

As cidades brasileiras vivem as consequências de uma urbanização incompleta e excludente, resultado de um planejamento urbano fortemente centralizador e conservador, que estrutura seus pressupostos na propriedade individual e absoluta, como a forma mais adequada de apropriação dos espaços, deixando de desenvolver direitos reais secundários, como a enfiteuse, que propõe uma funcionalização da propriedade, privilegiando o direito à moradia e à habitação através da proteção da posse.

A enfiteuse é o mais amplo instituto de direito real secundário, pois rompe o domínio em útil e eminente. Em poucas linhas, pode-se explicar a lógica do contrato enfitêutico da seguinte forma: um senhorio (que é um proprietário público ou privado) concede lotes de solo urbano ou rural aos enfiteutas que têm direito de posse, uso e gozo, inclusive de alienar e transmitir por herança os lotes recebidos com a permanente obrigação de pagar o foro (taxa anual) ao senhorio, além das obrigações de conferir uma real utilidade à terra, as chamadas "melhorias", no caso das enfiteuses urbanas: edificar; das rurais: plantar (Fonseca, 2016).

Como forma de visibilizar grupos esquecidos e privilegiar interesses extrapatrimoniais bem como diante da problemática do acesso à terra urbanizada no Brasil, vinculada à alta especulação imobiliária das cidades capitalistas, principalmente em suas áreas centrais, além do expressivo espraiamento do espaço urbano, ocasionando grandes e distantes periferias, é preciso pensar alternativas para um maior desenvolvimento dos direitos reais secundários. Essa é uma forma de inseri-los em uma ótica mais includente, funcional e social que represente de maneira mais fidedigna a atual sistemática jurídica e os postulados modernos do planejamento urbano, ou seja, de cunho participativo, democrático, estratégico e intersetorial.

Atendendo a estes pressupostos, o instituto da enfiteuse se insere de modo confortável em um rol de titularidades aptas a ampliar o acesso ao solo urbano bem como fomentar a segurança habitacional pela grande extensão de direitos de propriedade que dispõe o enfiteuta, além de trazer incluso o dever jurídico de funcionalizar o imóvel. Assim, o instituto pode servir como uma eficiente ferramenta de gestão urbana, já que contribui na garantia da função social da cidade e da propriedade. Com esse pensamento, questiona-se: a enfiteuse tem relação com o planejamento urbano? O instituto pode garantir melhores condições de acesso à terra urbanizada e lhe garantir melhor efetivação da função social da cidade e da propriedade?

Nesse sentido, o objetivo geral do presente artigo é compreender como o planejamento urbano estruturado sob o desenvolvimento de direitos reais secundários pode contribuir para democratizar o espaço urbano. A partir deste, traçam-se os objetivos específicos: delinear um breve histórico das raízes da propriedade liberal; discutir conceitualmente a propriedade e o exclusivismo proprietário como forma de estabelecer conexões com a necessária repersonalização dos direitos reais; e demonstrar os possíveis usos e aplicações da enfiteuse conjugada ao planejamento urbano. Para tanto, a pesquisa utilizou-se do método dedutivo e como procedimento metodológico utilizou-se a pesquisa bibliográfico-documental.

0 presente artigo está estruturado, além desta introdução, na seção 2 , que aborda um histórico acerca das bases da propriedade liberal, compreendendo a perspectiva absoluta e exclusiva que a propriedade adquiriu no ordenamento jurídico brasileiro; na seção 3 que discute-se como os postulados tratados na seção 2, excludentes e disfuncionais, não conseguem responder à atual dinâmica social e urbana e às 
múltiplas formas de propriedade existentes, fazendo-se necessário (re)personalizar esse direito. Em seguida, a seção 4 demonstra como o processo de desenvolvimento de direitos reais secundários, especificamente a enfiteuse, conectada ao planejamento urbano, guarda forte ligação com a proteção e democratização do acesso ao solo e moradia, pelas suas características de flexibilidade, justiça e participação. Por último, na seção 5, trazem-se algumas considerações finais, sugerindo que o não desenvolvimento dos direitos reais secundários está mais para uma escolha política, do que para uma inviabilidade jurídica.

\section{A propriedade de formulação jurídica liberal e o exclusivismo proprietário}

As modificações nos cenários econômicos e sociais que ocorreram nos séculos XVI, XVII e XVIII estão umbilicalmente ligadas ao contexto de mundo, pensamentos e ideias que criticaram fortemente $o$ mercantilismo, a Igreja Católica e o Absolutismo. 0 desenvolvimento urbano e industrial, reflexo do modo de produção capitalista no pós Revolução Industrial, que teve como fundamento a utilização de mão de obra assalariada, modificou drasticamente o quadro social da maioria dos países ocidentais através da exportação de um modelo proprietário, esvaziando grande parte da população campesina.

Como quadro ilustrativo e pela centralidade que ocupou no referido processo, traz-se o caso da Inglaterra. Neste país, essas modificações foram iniciadas ainda no século XVI, quando surgiu a Enclosure Acts ou "Lei de Cercamentos". Esse ato legislativo que ganhou força, sobretudo no século XVIII, significou recorrentes supressões da posse das terras que os camponeses detinham, de forma que a propriedade, antes constitutiva de obrigações, deveres de honra aos landlords, agora tornava-se constitutiva de imunidades e prerrogativas jurídicas. Na prática, eram privatizações de áreas "comuns", efetivadas pelos senhorios locais com a chancela dos monarcas e do Parlamento. 0 cenário passa do openfield para o closefield, caracterizando o início do período "liberal" na Inglaterra.

Nesse contexto, as relações de propriedade tinham se tornado fundamentais para um número cada vez maior de indivíduos, pois determinavam a liberdade real e a possibilidade de realização das potencialidades de cada um, ou seja, perspectivas de uma vida digna e maior exercício de direitos (Amadeo, 2015, p. 20).

0 período "liberal" na história inglesa, além de ser decisivo na formulação jurídica da propriedade absoluta, também tornou os sujeitos não proprietários potenciais inimigos do Estado, através de uma política de criminalização de condutas dos não proprietários. Essa política de criminalização teve como grande expressão legislativa a "Lei Negra" de 1723, dirigida contra os "negros de Waltham", que retiravam lenha e caçavam cervos nos domínios reais e eram considerados bandidos por tais condutas (Thompson, 1987, p. 33). Dessa forma, "[...] o Estado britânico, concordavam todos os legisladores do século 18, existia para preservar a propriedade e, incidentalmente, as vidas e liberdades dos proprietários" (Thompson, 1987, p. 21).

De fato, os usos e abusos da propriedade pelo seu titular perpassam pela lógica de possibilidade do exercício do direito real do proprietário, sem vinculação a nenhuma outra pessoa, é o "jus in re". Essa concepção tem suas raízes na perspectiva liberal e exclusivista da propriedade, que é muito forte no ordenamento jurídico brasileiro e resguardada pelo Código Civil (CC) de 2002: "Art. 1.231. A propriedade presume-se plena e exclusiva, até prova em contrário" (Brasil, 2002). Nessa conjuntura, a utilidade funcional tem menos força normativa, jurídica, social e até cultural do que a titularidade. Assim, o direito de ser proprietário e todas as imunidades advindas desse direito é maior e mais protegido juridicamente do que a efetiva destinação do bem imóvel.

Essa con(tra)dição jurídica está expressa nas cidades brasileiras, sobretudo, na medida em que justifica, reforça e mantém uma lógica de retenção especulativa da propriedade imobiliária que atinge níveis insuportáveis e ultrapassa em muito as condições socioeconômicas e de vida da maioria dos ocupantes da cidade. 0 grande capital faz da cidade um nó espacial de sua rede de garantias da mais- 
valia: "A produção e apropriação do espaço urbano não só reflete as desigualdades e as contradições sociais, como também as reafirma e reproduz" (Maricato, 2000, p. 170).

Blackstone (1753) escreve sobre esse "direito absoluto". 0 autor afirma que o direito à propriedade é uma das coisas que mais mexem com o imaginário humano: "Quem disse que através de uma folha de papel podíamos transmitir direitos proprietários quando não mais podemos/queremos exercer?" (Blackstone, 1753) ${ }^{1}$. A propriedade blackstoniana é absolutizada e imunizada de qualquer reflexão crítica; em termos práticos, seria a clássica propriedade liberal. 0 autor a descreve como um direito despótico exercido pelo homem com a total exclusão de qualquer outro indivíduo do universo (Blackstone, 1753). Nota-se que é uma perspectiva naturalista, de modo que seria um direito sacrossanto o único e verdadeiro fundamento acerca do domínio do homem sobre as externalidades. Ainda para Blackstone, a necessidade de estabelecimento em determinada área gerou a própria noção de propriedade, pois a terra produzia frutos em velocidade menor que o consumo humano. Então pensouse: é preciso utilizar a lavoura. Mas como esse homem trabalharia a terra e funcionalizá-la-ia se outro poderia chegar e tomar sua posse?

Partindo dessa questão, a sociedade civil introduziu as normatizações à propriedade, através de quadros regulatórios, como estatutos, governos, leis, punições e o exercício público dos deveres religiosos. Essa ocupação inicial é que dá o direito original à retenção permanente da propriedade, na concepção de Blackstone (1753). Ele defende que há um "consentimento tácito e implícito" de toda a humanidade que o primeiro ocupante se torna o proprietário absoluto e exclusivo.

Nesse sentido, o proprietário permanecerá no domínio do bem possuído até que tenha a intenção expressa de deixar de exercer esse domínio. Blackstone destaca a "conveniência recíproca", ou seja, o que era inútil para um homem era extremamente útil para outro e, pago o equivalente, essa propriedade era transmitida. Pode-se dizer que é o início de uma lógica de mercado imobiliário que torna "o espaço um produto e, nesta condição, revela-se na contradição valor de uso/valor de troca" (Carlos, 2018, p. 65).

Nesse mesmo raciocínio, outros autores, como Kersting (2005), também discutem essa concepção liberal da propriedade e vão além, falando de um processo de "humanificação". Assim, "[...] num sistema de propriedade absoluta, dos direitos de disposição capitalista, a propriedade não é mais algo exterior ao proprietário; o proprietário a incorporou, ela é seu corpo, ela é ele próprio" (Kersting, 2005, p. 44). Para Kersting (2005), há um destaque da "incorporação" da propriedade com o proprietário, formando o cerne da teoria absolutista. Assim, não é o bem que serve ao proprietário, mas o proprietário que serve ao bem; não há uma subjetividade nessa propriedade, mas tão somente as possibilidades de disposição contra tudo e contra todos. É nesse quadro que o autor chama a atenção para o processo de "coisificação" dos sujeitos sem propriedade.

A formação de um patrimônio irá importar, numa maior ou menor barreira, quando do acesso a direitos diversos. Rosencrantz (2008), analisando a questão, argumenta no sentido de que os direitos de propriedade são precisamente os que determinam a quantidade de recursos materiais que cada indivíduo socialmente concebido dispõe para exercer outros direitos: "Sem recurso é possível ter um Direito, mas não necessariamente desfrutá-lo" (Rosencrantz, 2008, p. 40).

Hespanha (2008) corrobora as teses acima e faz sua contribuição afirmando que a ciência jurídica existe somente para regular a propriedade, o objetivo seria "a distinção entre o "meu" e o "teu"” (Hespanha, 2008, p. 211). Talvez seja uma visão reducionista e até radical em alguma medida do direito enquanto ciência social; contudo, denuncia a importância dada aos direitos de propriedade na modernidade, contribuindo para a compreensão da lógica da proteção formal e imunização dessa propriedade que irá ser determinante no processo de segregação.

Esses postulados legitimam e justificam teórico-conceitualmente uma face de hierarquização social fortemente vista no solo urbano brasileiro e que é impactante em muitos aspectos, sobretudo, na seleção dos indivíduos que ocupam os espaços. Mora "bem" quem paga "bem". Essa distinção de tratamento

\footnotetext{
${ }^{1}$ Documento eletrônico em formulário contínuo que reconstitui uma obra antiga (1753) e não há paginação.
} 
aponta para uma segregação socioespacial que é patológica no Brasil, sendo que apropriação do solo urbano é só mais uma face dessa desigualdade.

O que precisa ser visto e discutido é a colocação da propriedade do solo urbano no campo da escassez e da segregação, reconhecendo que o Estado tem papel fundamental, pois somente ele pode aplicar os instrumentos legais já existentes e criar outros que visem à democratização do acesso ao solo. Para esse debate, é importante fazer uma breve discussão sobre a doutrina privatista em direitos reais, sobre sua necessária desmistificação, por não corresponder à realidade da sociedade e do próprio ordenamento jurídico e sobre a necessidade/utilidade de maior desenvolvimento dos direitos reais secundários, em específico, a enfiteuse, aliado ao planejamento urbano para que o uso e a ocupação da cidade tenham fins socialmente mais inclusivos. É o que se propõe nas linhas que se seguem.

\section{(RE)pensando os direitos reais}

O Código Civil de 2002 elenca em seu artigo 1.225 quais são os direitos reais sem, no entanto, caracterizá-los com exceção da propriedade em outro dispositivo. São direitos reais: propriedade, superfície, servidões, usufruto, uso, habitação, direito do promitente comprador do imóvel, penhor, hipoteca, anticrese, concessão de uso especial para fins de moradia, concessão de direito real de uso e a laje. No que tange à enfiteuse, o Código Civil de 2002 proibiu novas constituições. Contudo o Código Civil de 1916 permanece regendo as relações constituídas até a data de publicação do CC de 2002 e o referido instituto continua a se situar no centro das questões proprietárias no Brasil e América Latina (Fonseca, 2016). Para Maria Helena Diniz (2011, p. 58), “[...] pode-se compreender os direitos reais como sendo uma relação jurídica em que uma pessoa tem total domínio sobre a coisa possuída, podendo, assim, dela dispor, gozar e usufruir conforme sua própria capacidade." Importa notar que, em regra, são direitos absolutos no sentido de que podem ser opostos contra todos, ou seja, tem eficácia erga omnes.

Dentre os incisos do artigo 1.225 do CC/2002, o único direito real sobre coisa própria é o direito à propriedade, todos os demais se tratam de direitos sobre coisas alheias, também chamados de direitos reais secundários, limitados ou ainda de direitos reais funcionais nas palavras de Aronne (2013). Por tal motivo, o direito à propriedade toma contornos de grande importância e complexidade jurídico-social. É o que se pode chamar de "direito real por excelência". Todos os outros dependem dele direta ou indiretamente.

Desse modo, a perspectiva da propriedade enquanto "direito real por excelência" perpassa por um "senso comum jurídico" ultrapassado que atende a uma visão meramente privatista e que, no seu cerne, ainda trata a propriedade como um direito absoluto, exclusivo, excludente quase que no sentido exato do termo. Contudo, "[...] tal postura não corresponde à realidade da sociedade e do próprio sistema jurídico que a regula [...]" (Aronne, 2013, p. 18).

Partindo desse pressuposto, Ricardo Aronne inova no conceito de direitos reais para inseri-lo em uma ordem jurídica mais includente, funcional e social que represente de maneira mais satisfatória a atual sistemática jurídica. Fundamental para essa mudança de paradigma foi a inserção da função social da propriedade na CF de 1988 que, ao obrigacionalizar a propriedade, impõe uma "repersonalização" despatrimonializante do direito, pois é pacífico que no direito obrigacional não advém resquícios de absolutividade (Aronne, 2013, p. 84).

Nesse sentido, o fenômeno de "constitucionalização" dos direitos reais resultou em uma ampliação na forma de enxergar essa categoria jurídica. Essa visão mais abrangente visibilizou grupos historicamente esquecidos, ou seja, não titulares de bens, e privilegiou interesses extrapatrimoniais. Para Aronne (2013), uma releitura "repersonalizante" do Código Civil desloca o enfoque protetivo do patrimônio para a dignidade da pessoa humana. Dessa forma, Aronne conceitua direitos reais como

[...] ramo do Direito Civil destinado à regulação sociopatrimonial da posse, titularidade e domínio, com larga projeção e influência dos demais campos do Direito (agrário, urbanístico, ambiental, administrativo, biodireito, contratos, dentre outros); pois largamente influenciado e influente no 
sistema jurídico como totalidade (aberta), a partir do reconhecimento de sua unidade axiológica, com epicentro constitucional (Aronne, 2013, p. 178).

Entende-se que esta é uma das melhores definições encontradas atualmente sobre direitos reais por considerar a propriedade numa perspectiva integrada, social, funcional, indeterminista, libertadora e inclusiva. $\mathrm{O}$ autor reconhece os direitos reais como interconectados, influenciados e influenciando, aos demais campos do direito, destacando sua unidade axiológica, isto é, valores constitucionais como epicentro norteador. A Constituição deve orientar o entendimento, leitura, interpretação e aplicação dos institutos de direitos reais e guardar coerência material com o atual sistema jurídico. Essa lógica rompe com a visão tradicional do direito romano em que os únicos atores da relação nos direitos reais eram o bem e seu titular. Essa releitura favorece o processo de desenvolvimento de direitos reais secundários e guarda forte ligação com a proteção e democratização do acesso ao solo e moradia através do planejamento urbano. Sobre este ponto trata-se no tópico seguinte.

\section{A interface entre planejamento urbano e enfiteuse}

Planejamento urbano, segundo Pujadas \& Font (1998), é “[...] uma organização do uso da terra com base na redistribuição de oportunidades de expansão e detecção de necessidades, potencialidades, limitações e vantagens comparativas e competitivas" (Pujadas \& Font, 1998, p. 12). Seria a configuração, no território, dos programas, planos e políticas econômicas, sociais, culturais e ecológicas da sociedade. Para Camargo (2009), o planejamento é caracterizado pela interferência direta na organização espacial, isto é, as formas geográficas são reestruturadas de acordo com o interesse do planejador. É preciso ter em mente que esse interesse não é isento, ou seja, durante todo o processo de planejamento e execução, essa organização está pautada na tentativa de inserção desse território em uma ordem econômica, de forma que essa gestão não é meramente econômica, mas ideológica.

Dentro dessa realidade, no Brasil, esse conceito teve maior desenvolvimento, produção legislativa e acadêmica, no período anterior à Constituição Cidadã de 1988. Temporalmente, pode-se situar como marco desse desenvolvimento a elaboração da Política Nacional de Desenvolvimento Urbano em 1973, ainda sob a égide do regime militar, fortemente autoritário, centralizador e conservador.

Durante o regime militar, o planejamento urbano foi conservador, porque representou a manutenção da ordem econômica e social vigente no Brasil com todas as suas iniquidades, e autoritário, porque as decisões foram tomadas por um pequeno grupo de pessoas e imposto à população (Souza \& Rodrigues, 2004, p. 42)

Esses pressupostos orientaram o planejamento urbano no país e o desenvolvimento de projetos, políticas e programas alienígenas que, quando executados, contribuíram para agravar o quadro de desigualdades sociais no Brasil e impactaram a atual urbanização incompleta e excludente (Maricato, 2000; Souza; Rodrigues, 2004). Imersa nesse padrão de planejamento urbano, a cidade "[...] torna-se, uma mercadoria, como, em tese, todos os produtos do trabalho humano" (Carlos, 2018, p. 53), reforçando seu caráter econômico sustentado pelo valor de troca, em detrimento do seu valor de uso, alimentando, por conseguinte, a valorização especulativa da terra (Rolnik \& Klink, 2011).

De fato, essa contradição não se estabelece entre o capitalismo e o Estado, mas entre o capitalismo, as plenas cidadanias e as democracias substantivas, como afirmou Bourdieu (2014). Neste dilema, transfere-se a questão da legitimação da ordem, deslocando-se das "lógicas do Estado" para as "lógicas da sociedade civil", processo pelo qual o Estado segue legitimando as necessidades do mercado numa contraditória e operante lógica de segregação, através, por exemplo, de um planejamento urbano projetado e executado dentro da lógica da propriedade plena e individual. Assim, o Estado legitima, justifica e mantém a segregação socioespacial, ao mesmo tempo que tenta solucionar a questão. Sobre esse aspecto, Maricato (1996) afirma que "[...] a produção ilegal das moradias e o urbanismo segregador 
são características dos investimentos públicos, que favorecem o mercado concentrado e restrito" (Maricato, 1996, p. 43.)

Precisamente pós-Constituição de 1988, o conceito de planejamento urbano ganhou maior problematização política e social, quando ficou clara a importância do desenvolvimento de políticas urbanas de organização do espaço como forma de erradicar desigualdades. Assim, "[...] a luta pelo acesso à cidade foi um importante movimento de reconhecimento da cidadania da população vulnerável, suscitando no Brasil o movimento pela reforma urbana" (Santos, 2012. p. 65). Com essa luta, foram introduzidos, via emenda popular, dois artigos na Constituição Federal de 1988 (arts. 182 e 183). Essa mudança de paradigma jurídico exige que haja um tratamento das cidades como bem público, cujo todo o processo de planejamento esteja vinculado ao interesse coletivo e efetivamente garanta a participação popular como pressuposto de planejamento e não como clientelismo (Lefebvre, 2001; Santos, 2012; Camargo, 2009).

Sob este aspecto cabe fazer uma referência ao Estatuto das Cidades, Lei n. 10.257/2001, instrumento legal de governança da terra, pioneiro e inovador, que é elaborado visando regulamentar os citados artigos 182 e 183 da Constituição Federal de 1988. A referida lei representa a consolidação de um novo paradigma jurídico e social: o da função social da propriedade e da cidade (Fernandes, 2013).

Contudo, não é objetivo deste trabalho aprofundar-se na análise dos instrumentos urbanísticos e de direitos reais trazidos no Estatuto das Cidades (Brasil, 2001), mas destacar a inegável evolução legislativa que a lei representou e aspectos que, apesar de teoricamente elogiáveis, pouco contribuem para uma real democratização dos espaços. Como exemplo, pode-se citar a opção do legislador em ampliar o instituto de direito real secundário da "superfície", já expressamente previsto no Código Civil de 2002 (Brasil, 2002), sem, no entanto, dar-lhe a profundidade e extensão necessárias a uma real ampliação do acesso à moradia e habitação. Na prática, as disposições em relação ao "direito de superfície" constantes no Estatuto das Cidades (Art. 21 caput e $\S 2$ o; Art. 22, II; e Art. 24), ao exigir escritura pública na concessão e, ao deixar de estabelecer percentuais mínimo/máximos de valores nas concessões onerosas, por exemplo, reforçam a lógica de burocratização e onerosidade nas relações proprietárias que atendem a interesses externos e de estamentos de maior renda na sociedade.

Uma alternativa para modificar o quadro retratado seria aproximar o máximo possível, em nível legislativo, o instituto do "direito de superfície" ao instituto da "enfiteuse", pela ampla possibilidade de negociação de direitos e obrigações entre os contratantes, larga extensão de direitos proprietários concedidos ao enfiteuteta, segurança da posse, baixa onerosidade e menor burocratização das transmissões.

Nesse sentido, o planejamento urbano precisa ser um projeto de Estado, um instituto social e político e não um direito enxergado individualmente. Por esta razão, toda a sua estrutura jurídica "[...] precisa refletir normas e valores que não são totalmente expressas por referência ao valor de mercado dos direitos de propriedade" (Singer, 2009, p. 1010). 0 Estado, através de quadros normativos reguladores, que antes só estava preocupado em preservar a propriedade, sob o paradigma da repersonalização, deve transitar para um "Estado social, promocional, retirado de um estado de inércia em frente das relações interprivadas, para passar a intervir nas mesmas" (Aronne, 2013, p. 42), alterando, assim, as bases de estruturação do planejamento urbano.

Nesse cenário, a enfiteuse torna-se uma alternativa possível para estruturar o planejamento urbano e contribuir para a superação de contradições e democratização do solo por permitir, entre outras possibilidades, a conjunção de titularidades no imóvel, fortalecendo o direito à moradia e habitação, maior celeridade nos processos de gestão, por ter uma menor complexidade técnico-logística e menor onerosidade na transmissão. Pisarello (2001) argumenta no sentido de ampliar as formas de acesso e segurança na moradia, em que os direitos habitacionais não se efetuem só no regime de propriedade, “[...] já que existem outros títulos de uso ou desfrute possíveis e legítimos, como o arrendamento e usufruto" (Pisarello, 2001, p. 97). Essa perspectiva se conecta com os argumentos de Robilant (2014) ao afirmar que o planejamento tecnicista, estruturado exclusivamente no direito à propriedade, subestima o dinamismo social, as necessidades dos governos locais, as preferências dos atores privados e superestima 
a capacidade dos governos locais de prever novas necessidades regulatórias, o que potencialmente diminui a participação popular.

A experiência de conjugação da enfiteuse ao planejamento urbano foi/é vista, por exemplo, na Holanda e na França. Robilant (2014) atribui essa eficiente gestão de terras enfiteuticadas como resultado do impacto de novos valores proprietários decorrente das deliberações mais livres e contratuais que impõem mudanças na rigidez do numerus clausus de direitos reais, sem possibilidade de a enfiteuse ensejar novo "enfeudamento" nas relações pessoais, o instituto se apresenta dinâmico e apto para acesso e gestão da propriedade (Robilant, 2014). Mais que uma categoria jurídica, a enfiteuse é uma lógica proprietária. Fonseca (2011) define enfiteuse como "uma cisão no direito de propriedade, a mais profunda delas, pois rompe o "domínio" em "útil" e "direto" ou eminente" (Fonseca, 2011, p. 34). Em breves palavras, funciona da seguinte forma: o senhorio entrega, desde a fundação da povoação, lotes do solo urbano e rural aos enfiteutas que têm direito de posse, uso e gozo, inclusive, de alienar e transmitir por herança os lotes recebidos com a eterna obrigação de pagar o foro ao senhorio, além das obrigações de conferir uma real utilidade da terra às chamadas "melhorias", no caso das enfiteuses urbanas: edificar; das rurais: plantar.

Ainda para Fonseca (2016), as "melhorias" guardam "[...] conteúdo semelhante ao da função social da propriedade". Tepedino (2004) segue linha de entendimento análoga, mas ressalva que a função social da propriedade é muito mais extensa e, sendo assim, a enfiteuse não conseguiria sintetizar e não alcançaria todos os seus complexos elementos. Para Aronne (2013), em oposição aos autores, a enfiteuse é a própria antecipação da função social da propriedade. Seria, em termos, uma resposta completa, tanto em extensão quanto em profundidade, aos anseios do Estatuto das Cidades e da própria Constituição Federal de 1988, no que tange à previsão de que a propriedade urbana e rural irá atender a uma função social. As disposições e natureza jurídica da enfiteuse consubstanciam de maneira mais concreta, do ponto de vista dogmático, a previsão constitucional, bastante abstrata e passível de interpretações deturpadas, de função social da propriedade e da cidade.

Além desses estudiosos, outros autores, como Melo (2003), enxergam a enfiteuse como "[...] um instituto anacrônico e absolutamente divorciado do paradigma da função social da propriedade [...]" (Melo, 2003, p. 182), uma vez que confere direitos patrimoniais a um indivíduo que não está dando à terra a destinação social. Essa concepção não parece a mais acertada, tendo em vista que a natureza jurídica da enfiteuse prevê tão somente uma contrapartida financeira módica e anual, de forma que, nem de longe, tal contrapartida atende a aspectos de especulação imobiliária e acumulação. Em verdade, a inserção de obrigações no regime enfiteutico instrumentaliza a própria função social (Aronne, 2001).

Hunter (1803) relembra que a enfiteuse era atribuída aos arrendamentos longos ou perpétuos de terras tomadas em guerra concedidos pelo Estado romano. A renda dada por essa terra foi chamada de vectigal e a própria terra de vectigalis. As vantagens do arrendamento perpétuo, nestes termos, foram largamente utilizadas por corporações privadas, igrejas e entes públicos por aliviar a preocupação com a gestão das terras, mesmo que o arrendamento não representasse vultosos ganhos financeiros. Registrase que arranjos semelhantes aos descritos por Hunter (1803) são possíveis de serem encontrados na atualidade em países como a China, a Inglaterra e a Holanda. Esses países possuem grandes extensões de seus territórios, em alguns casos, a quase totalidade, sob enfiteuse e concedem os lotes às famílias, edificados ou não, para moradia e habitação por longos períodos a preços módicos.

Van Erp \& Akkermans (2012) diferenciam a enfiteuse do direito de usufruto por aquele ser de caráter potencialmente perpétuo e dessa forma conferir mais segurança na relação estabelecida. Já Bocken \& Bondt (2001), comentando sobre o contexto de inserção da enfiteuse na Bélgica em 1824, a partir da influência holandesa, destacam que os contratos enfitêuticos, naquele território, não podiam ter um caráter perpétuo, mas tão somente contratos de longa duração, com lapso temporal mínimo de 27 anos e máximo de 99 anos. A capacidade de mutação do instituto e a possibilidade de contratualmente alterar seus aspectos acessórios sem desnaturar seu cerne, qual seja a funcionalização do bem, o torna apto e eficaz para atender a dinâmica urbana e corresponder às múltiplas necessidades dos atores que, mesmo 
sem o reconhecimento legislativo de outras formas de propriedade, estão a todo momento fazendo (re)arranjos entre si.

As reformas liberais e sua onda desamortizadora em relação à propriedade determinaram a tônica dos códigos civis no ocidente e levaram à supressão, a nível legislativo, do instituto da enfieuse em diversos ordenamentos jurídicos, tal como na França, Holanda, Portugal e Argentina. Sobre este aspecto, Robilant afirma que: "A enfiteuse foi primeiro abandonada e depois reintroduzida devido a uma mudança nos valores associados à propriedade e a necessidade de permitir formas de propriedade que promovam o uso eficiente e "participativo" dos recursos" (Robilant, 2014, p. 389).

A lógica proprietária funcionalista que orienta a constituição da enfiteuse era/é vista como resquício odioso da feudalidade e, por isso, desconectada com a perspectiva privatista/patrimonialista que sustenta as legislações liberais, ou seja, a unificação de todos os poderes e prerrogativas proprietários em um único titular (Fonseca, 2016). Contudo, a dinâmica social e urbana mantiveram as relações proprietárias baseadas em arranjos complexos que se adequam, confortavelmente, aos pressupostos da enfiteuse, o que contribuiu para seu retorno, inclusive nos países que outrora a aboliram, ainda que renovada ou com outros nomes iuris.

No Brasil, o Código Civil de 1916 tinha um capítulo inteiro dedicado a esse instituto que regulamentava, desde a sua constituição até sua transmissão, as obrigações dos envolvidos na relação. Com o advento do Código Civil de 2002, o instituto foi extinto do códex e houve uma proibição de constituição de novas enfiteuses. Entretanto, as já existentes quando do advento do Código Civil de 2002 seguem sendo reguladas pelas disposições do Código Civil de 1916. Importa deixar registrado que esta é a realidade de centenas de cidades brasileiras, tais como: Sousa-PB, Salgueiro-PE, Pau dos Ferros-RN, Alexandria-RN, Flores-PE, São José do Egito-PE, Recife-PE, Olinda-PE, Paraty-RJ, Rio de Janeiro-RJ, Barueri-SP, Santana de Parnaíba-SP, Cruz das Posses-SP (Piccinato Junior \& Salgado, 2016), dentre outras. Assim, vale questionar: quais as estratégias práticas de articulação da enfiteuse no planejamento urbano, já que ela faz parte de nossa realidade? Tratemos, pois, sobre.

\section{Por onde começar?}

Robilant (2014), estudiosa da temática dos Direitos Reais, destaca os benefícios trazidos pela enfiteuse enquanto ferramenta para gestão participativa de interesses coletivos ligados à propriedade: flexibilidade, justiça e participação. Essas características, somadas a sua lógica de sobreposição de titularidades, funcionalização e perpetuidade, sem significar, necessariamente, que não possam haver prazos nos contratos enfitêuticos, prometem uma alternativa ao planejamento do uso da terra mais eficiente e justo, em que a propriedade plena não seja a única forma de apropriação.

Esse quadro oportuniza que os governos locais, associações civis, moradores, representantes comunitários e demais partes interessadas negociem planos específicos de uso da terra e personalizem o conteúdo dos direitos de propriedade " [...] é o que os estudiosos de estudos urbanos europeus chamam de 'governança cooperativa' ou 'contingente' do uso da terra" (Robilant, 2014, p. 402). Em outras palavras, seria a propriedade deliberativa. Inseridos nesse quadro de flexibilidade, justiça e participação, características da enfiteuse e de outras formas deliberativas de propriedade, o presente tópico apresenta possíveis aplicações da enfiteuse conectada ao planejamento urbano em diversos aspectos. Para fins meramente explicativos, neste artigo, dividiram-se as possibilidades de aplicação do instituto em seis dimensões, são elas: legislativa, habitacional, educacional, urbanística, comercial e jurídica.

Como dimensão legislativa, propõe-se uma retomada da lógica proprietária da enfiteuse, através, por exemplo, de alteração na Lei 10.257/2001, o Estatuto das Cidades, para aproximar o instituto do direito de superfície da natureza jurídica da enfiteuse e, dessa forma, atender a necessária repersonalização dos direitos reais, para inseri-los em uma ordem mais integrada, social, funcional, indeterminista, libertadora e inclusiva (Aronne, 2013). Outra possibilidade legislativa que atenderia a este pressuposto, seria uma reintrodução da enfiteuse no rol dos direitos reais do artigo 1.225 do Código Civil de 2002. Como já se 
postulou, existem institutos de direito real no ordenamento jurídico brasileiro que se assemelham à enfiteuse. Contudo nenhum consegue contemplar sua extensão e profundidade. A enfiteuse, para além de um instituto jurídico, é um paradigma proprietário. As experiências internacionais na Holanda e França, por exemplo, mostram que as abolições do instituto da foram sucedidas por reintroduções para atender a dinâmica social (Fonseca, 2016). Mesmo que com outros nomes iuris, as reintroduções preservaram os pressupostos e natureza jurídica da enfiteuse clássica.

Na dimensão habitacional, destaca-se a lógica do cooperativismo habitacional. Comprar a plena propriedade é muito oneroso, muito mais que simplesmente edificar e pagar uma taxa percentual sobre o valor da terra, anualmente, durante longos períodos. Essa lógica democratiza o acesso ao solo urbano, dificulta o processo de segregação ao mesmo tempo que dinamiza o mercado de solos. Já existem projetos desse tipo na Alemanha, que pretende assentar mais de 150 mil pessoas até 2025 (Fonseca, 2016). No Brasil, esse cenário poderia ser implementado em uma versão análoga ao que ocorre em países como Estados Unidos, Reino Unido, Quênia e Canadá com os community land trust, que se caracterizam por serem espaços de moradia social autogerida, com garantia permanente de acesso, através da regulação de preços e reinvestimento cíclico dos módicos valores pagos pelas famílias pela aquisição da moradia. Os locais para estabelecimento dessas moradias sociais poderiam ser, por exemplo, áreas urbanas centrais abandonadas e/ou imóveis inutilizados. Bastaria, para tanto, que o estado desapropriasse o domínio útil dos referidos imóveis, de forma que os proprietários absenteístas não perderiam todos os seus poderes proprietários, o que tendencialmente iria diminuir os conflitos do referido processo.

No que tange à dimensão educacional, pela característica de interdisciplinaridade que orienta o planejamento, de grande importância seria uma reformulação da matriz curricular dos cursos de nível superior que formam profissionais que lidam de maneira mais direta com o planejamento urbano, tais como: Arquitetura e Urbanismo, Engenharia Civil, Geografia, Gestão de Políticas Públicas, Direito e outros. Essa reforma curricular seria no sentido de fomentar uma mudança de olhar e de interpretação, objetivando modificar a leitura privatista da propriedade para uma leitura mais funcional, qualificando os operadores do planejamento. Disciplinas específicas atenderiam de maneira mais satisfatória, por exemplo, o desenvolvimento de direitos reais secundários que respondem de maneira mais fiel a própria função social da propriedade e da cidade.

Outro aspecto que merece relevo é o necessário desenvolvimento de políticas de qualificação dos atores (públicos e privados) que fazem a gestão de patrimônios enfitêuticos Brasil afora. A mera alteração legislativa reintrodutória da enfiteuse, apesar de benéfica e necessária, não é condição essencial e única para o desenvolvimento de direitos reais secundários no Brasil, pois existem centenas de localidades em que há ocorrência do instituto e as disposições do Código Civil de 1916, nesses casos continuam válidas e aptas a democratizar os espaços a partir de uma personalização dos direitos proprietários. Contudo, o amplo desconhecimento, do ponto de vista técnico, sobre a temática, se configura como uma grande barreira.

Já na dimensão urbanística, a enfiteuse poderia ser uma valiosa ferramenta de gestão na questão dos vazios urbanos e imóveis abandonados, ou seja, propriedades inutilizadas/disfuncionais que poderiam ser funcionalizadas pelo Estado através da desapropriação do domínio útil do imóvel para a construção, por exemplo, de moradias populares ou para o desenvolvimento de uma agricultura intraurbana, que poderia contribuir para segurança alimentar de famílias de baixa renda. Os benefícios de utilização da enfiteuse, neste caso, se configuram, sobretudo, pela não perda da totalidade dos poderes de propriedade por parte dos proprietários absenteístas, o que potencialmente diminuiria os conflitos envolvidos (sociais, jurídicos e técnicos) bem como pela menor onerosidade do processo para o estado, que não precisaria arcar com altos valores à titulo de indenização, como nas desapropriações clássicas. 0 proprietário seria indenizado somente pelo valor do domínio útil do imóvel $117 \%$ do valor do domínio pleno). 0 mesmo raciocínio pode ser aplicado nos casos de desapropriação de terras em áreas de interesse do estado para preservação ambiental, além das vantagens já citadas, o aumento das áreas de preservação ambiental nas cidades seria mais um fator benéfico. 
A dimensão comercial é importante para demonstrar que as disposições da enfiteuse nem de longe visam um engessamento das relações econômicas; pelo contrário, o instituto pode ser útil para fomentar o processo de desenvolvimento regional na medida em que pode ser aplicado a contratos de locação empresarial pela sua característica de longa duração e possibilidade de sublocação, transformação e transferência, que interessam ao setor empresarial. Ainda neste panorama comercial, especificamente no que tange às possibilidades de negociação junto aos bancos, a enfiteuse pode representar grandes descontos, no valor de hipotecas, em troca do domínio "potencial" do imóvel, em favor dos bancos, assegurados à família o direito à moradia e possibilidade de total resgate.

Por último, tem-se a dimensão jurídica. Sob este aspecto, a enfiteuse poderia ser uma eficiente auxiliar para diminuir os conflitos envolvendo propriedade e seus potenciais titulares. Por exemplo, nos processos de usucapião, em caso de procedência do pedido, o réu (proprietário pleno) não perderia a propriedade, mas tornar-se-ia detentor do domínio direto (ou potencial) e o autor da ação de usucapião tornar-se-ia detentor do domínio útil. Já há precedentes judiciais em Portugal e na Inglaterra nesse sentido. Este mesmo cenário, poderia também auxiliar na questão da reforma agrária no Brasil. Os conflitos judiciais que envolvem direitos proprietários, em geral, são longos e dispendiosos e, ao final, sempre haverá um lado que perderá a totalidade dos seus interesses e poderes em relação ao bem, ao imóvel. Esse mecanismo não faz sentido quando há uma possibilidade apta, como a enfiteuse, de harmonizar tais interesses e atender, sobretudo, a princípios de privilégio do direito à moradia e habitação.

É importante destacar que as dimensões, usos e aplicações, aqui expostas, não encerram o debate e nem esgotam as possibilidades existentes. Em verdade, considerando a complexidade das relações estabelecidas bem como as necessidades de cada território a ser desenvolvido, o instituto deve ser debatido e ajustado, como forma de potencialmente garantir a minimização das desigualdades socioespaciais.

\section{Considerações finais}

O liberalismo foi decisivo na absolutização dos direitos de propriedade. Nessa lógica, o Estado Moderno fora constituído para preservar essa imunização e, de maneira reflexa, a vida e a liberdade dos proprietários. Essa perspectiva influenciou a codificação dos direitos de propriedade no ocidente e favoreceu uma segregação socioespacial que é patológica no Brasil. A grande questão é a propriedade colocada no campo da raridade e da escassez como forma de manter o status quo do mercado imobiliário. Por isso é necessária uma atuação firme do Estado, via planejamento urbano, no sentido de equalizar as forças contraditórias que atuam no território e aplicar os instrumentos legais já existentes, além de criar outros visando sempre à democratização do acesso ao solo.

Como visto, as possíveis aplicações da enfiteuse sugerem um alto nível de mutabilidade e sobrevivência do instituto e demonstram que ele se encontra apto a contribuir para o planejamento, execução e avaliação de políticas públicas que visem, dentre outros aspectos: desenvolvimento de projetos de habitação acessível e inclusiva, novos arranjos proprietários em processos de desapropriação, minimização das contradições sociais, recuperação da mais-valia fundiária em regiões subdesenvolvidas, democratização do solo urbano, entre outros. Nesse cenário, (re)significar os direitos reais, por meio de um rompimento com a visão clássica do direito romano privatista, exclusiva, excludente e absoluta, em que os únicos "agentes" interessados na relação são o próprio bem e seu titular, é medida imperativa para atingir os objetivos de minimização das desigualdades sociais do ordenamento territorial.

Como alternativa às formas tradicionais de estruturação do planejamento urbano, propõe-se um maior desenvolvimento de direitos reais secundários - em específico, a enfiteuse - , que permite, entre muitas outras possibilidades, a conjunção de titularidades no imóvel, maior celeridade nos processos de gestão e menor onerosidade na transmissão. Essa lógica de sobreposição de titularidades, 
funcionalização e perpetuidade aponta para uma maior eficiência e justiça no trato do território. Esse quadro irá ampliar a participação popular nos planos de negociação dos usos da terra além de permitir personalização do conteúdo dos direitos de propriedade.

Com vontade política e reconhecimento da necessidade social que existe, é possível (re)organizar o espaço urbano. Dos desafios que configuram o desenvolvimento da enfiteuse no planejamento urbano, talvez o maior deles seja impedir que o instituto seja capturado por forças externas, orientadas pelo capital nacional e internacional e, dessa forma, seja aplicado de forma diversa da que se propõe. Impedir essa captura perpassa pelo desenvolvimento de reformas estruturantes no processo de formulação, execução e avaliação de políticas públicas no Brasil, ou seja, garantir que os atores sociais consigam efetivamente impactar a tomada de decisão por parte dos gestores e que esse impacto seja dissociado de aspectos de renda e capital político.

Dessa maneira será possível desenvolver uma democracia deliberativa que esteja apta a albergar formas de propriedade baseadas na negociação entre os participantes da relação de direito real. Por mais que possa parecer utópico, a experiência internacional na Holanda, França, Belgica, EUA e Reino Unido, por exemplo, demonstra, de maneira bastante clara, que a possibilidade de desenvolver tais formas de propriedade é concreta. Embora se compreenda o Brasil dentro de um contexto de capitalismo periférico, historicamente regido por interesses internacionais exógenos às necessidades do país, é possível democratizar os espaços e reordenar as nossas cidades.

\section{Agradecimentos}

Fundação de Apoio à Pesquisa do Rio Grande do Norte - FAPERN e Secretaria de Estado do Meio Ambiente e dos Recursos Hídricos do Rio Grande do Norte - SEMARH.

\section{Referências}

Amadeo, J. (2015). As raízes do liberalismo: liberdade e propriedade no pensamento político do século XVII. Perspectivas, 46(1), 9-36. Recuperado em 8 de janeiro de 2020, de https://periodicos.fclar.unesp.br/perspectivas/article/view/10052/6607

Aronne, R. (2001). Os direitos reais na constitucionalização do direito civil. Direito \& Justiça, 39(2), 175-196. Recuperado em 8 de janeiro de 2020, de http://revistaseletronicas.pucrs.br/ojs/index.php/fadir/article/view/15141

Aronne, R. (2013). Propriedade e domínio: a teoria da autonomia: titularidades e direitos reais nos fractais do direito civil-constitucional (2a ed., Vol. 1). Porto Alegre: Livraria do Advogado.

Blackstone, W. (1753). Commentaries on the laws of England in four books (Vol. 1). Recuperado em 8 de janeiro de 2020, de http://oll.libertyfund.org/titles/2140

Bocken, H., \& Bondt, W. (2001). Introduction to Belgian law. Bruxelas: Kluwer Law International.

Bourdieu, P. (2014). Sobre o estado. São Paulo: Companhia das Letras.

Brasil. (2001, 10 de julho). Estatuto das Cidades Lei no. 10.257, de 10 de julho de 2001. Regulamenta os arts. 182 e 183 da Constituição Federal, estabelece diretrizes gerais da política urbana e dá outras providências. Brasília: Diário Oficial da União. Recuperado em 8 de janeiro de 2020, de http://www.planalto.gov.br/ccivil_03/leis/LEIS_2001/L10257.htm

Brasil. (2002, 10 de janeiro). Código Civil lei no 10.406, de 10 de janeiro de 2002. Institui o Código Civil. Brasília: Diário Oficial da União, seção 1. 
Camargo, L. H. (2009). Ordenamento territorial e complexidade: por uma reestruturação do espaço social. In: F. G. Almeida \& L. A. S. Alves (Eds.), Ordenamento territorial: coletânea de textos com diferentes abordagens no contexto brasileiro (Vol. 1, pp. 288). Rio de Janeiro: Bertrand Brasil.

Carlos, A. F. A. (2018). Crise urbana. São Paulo: Contexto.

Diniz, M. H. (2011). Curso de direito civil brasileiro: direito das coisas. São Paulo: Saraiva.

Fernandes, E. (2013). Estatuto da cidade mais de dez anos depois: razão de descrença, ou razão de otimismo? Revista da UFMG, 20(1), 212-233.

Fonseca, P. H. (2011). A enfiteuse e função social do solo urbano: a regularização local e popular. In Anais do XX Congresso Nacional do Conselho Nacional de Pesquisa e Pós-graduação em Direito (pp. 1717-1741). Manaus: CONPEDI.

Fonseca, P. H. (2016). Além do feudo e do burgo: a enfiteuse como instituto mutante, suas possibilidades e limites (Tese de doutorado). Universidade Federal de Pernambuco, Recife.

Hespanha, A. M. (2008). Introdução histórica ao direito (5a ed., Vol. 1). Lisboa: Fundação Calouste Gulbenkian.

Hunter, W. A. A. (1803). Systematic and historical exposition of roman law in the order of a code (4a ed., Vol. 1).

Londres: Sweet \& Maxwell.

Kersting, W. (2005). Liberdade e liberalismo (Vol. 1). Porto Alegre: EDIPUCRS.

Lefebvre, H. (2001). O direito à cidade. São Paulo: Centauro.

Maricato, E. (1996). Metrópole na periferia do capitalismo. São Paulo: Hucitec.

Maricato, E. (2000). As ideias fora do lugar e o lugar fora das idéias: planejamento urbano no Brasil. In O. Arantes, C. Vainer \& E. Maricato (Orgs.), A cidade do pensamento único; desmanchando consensos (pp. 121-192). Petrópolis: Vozes.

Melo, M. A. B. (2003). Anotações sobre os aspectos intertemporais do direito das coisas no Novo Código Civil. Revista EMERJ, 6(24), 292-304.

Piccinato Junior, D., \& Salgado, I. (2016). A conflituosa relação entre igreja e poder público municipal no gerenciamento da terra urbana - estudo de caso: Cruz das Posses, São Paulo. urbe. Revista Brasileira de Gestão Urbana, 8(2), 228-241. http://dx.doi.org/10.1590/2175-3369.008.002.A005.

Pisarello, G. (2001). Los derechos sociales en el constitucionalismo moderno: por una articulación compleja de las relaciones entre política y derecho. In: M. CARBONELL, J. A. Cruz Parcero \& R. Vázquez (Orgs.), Derechos sociales y derechos de las minorías (pp. 113-138). México: Porrúa/UNAM

Pujadas, R., \& Font, J. (1998). Ordenación y planificación territorial. Madrid: Sistesis.

Robilant, A. D. (2014). Property and deliberation. The numerus clausus principle, new property forms and new property values. The American Journal of Comparative Law, 62(2), 367-416.

http://dx.doi.org/10.5131/AJCL.2014.0004.

Rolnik, R., \& Klink, J. (2011, março). Crescimento econômico e desenvolvimento urbano: por que nossas cidades continuam tão precárias? Novos Estudos Cebrap, 89, 89-109. http://dx.doi.org/10.1590/S010133002011000100006.

Rosencrantz, C. (2008). Restricciones a los derechos e propiedad em circunstancias de escassez. In: H. Alviar Garcia, M. A. Abarca, P. Bergallo, D.B. Maldonado, A. Bullard G., L.C. Becerra, A.P. Barcellos, A. Corrêa, M.I.D.T. Huerta, C. Salles, E.F. Torres, L. S. Grosman, A. Madrazo, N. Novogrodsky, A.M.O. Nusdeo, E. Pasquel, C.P. Gouvêa, M.R. Sanchez, C. M. Rose, C. Rosenkrantz, L. Sierra \& M. Taussig-Rubbo, Derecho y propiedad. Seminário en Latinoamérica e Teoría Constitucional y Política - SELA. Buenos Aires: Libraria.

Santos, A. M. S. P. S. (2012). Planejamento urbano: para quê e para quem? Revista de Direito da Cidade, 4(1), 91119. http://dx.doi.org/10.12957/rdc.2012.9699. 
Singer, J. W. (2009). Democratic estates: property law in a free and democratic society. Cornell Law Review, 94(4), 1009-1082. Recuperado em 8 de janeiro de 2020, de

https://scholarship.law.cornell.edu/cgi/viewcontent.cgi?article=3140\&context=clr

Souza, M. L., \& Rodrigues, G. B. (2004). Planejamento urbano e ativismos sociais (136 p., Coleção Paradidáticos; Série sociedade, espaço e tempo). São Paulo: UNESP.

Tepedino, G. (2004). Temas de direito civil (Vol. 1, 3. ed.). Rio de Janeiro: Renovar.

Thompson, E. P. (1987). Senhores e caçadores. A origem da Lei Negra (Trad. Denise Bottmann). Rio de Janeiro: Paz e Terra.

Van Erp, S., \& Akkermans, B. (2012). Cases, materials and text on property law (Vol. 1). Portland: Bloomsbury Publishing.

Editor responsável: Fábio Duarte

Recebido: Jan. 08, 2020

Aprovado: Jun. 22, 2020 